\title{
APPENDIX.
}

\section{ON THE NEED FOR EUGENIC REFORM.}

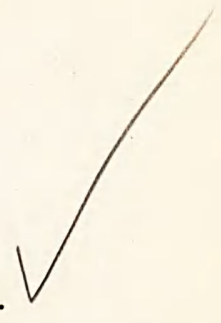

By Major Leonard Darwin, President of the Eugenics

Education Society.

(Conjoint meeting with the Medico-Chirurgical Society to inaugurate

the new meeting-place, Wednesday, 29th October 1913.)

LINNeUS, writing in the middle of the eighteenth century, declared that species are now as numerous as when Providence first created them in the beginning, and that, in accordance with the laws of generation then laid down, the beings originally created produced only forms similar to themselves, with the result that the species now with us are no more numerous than they were at first. In writing thus this great naturalist was only expressing the belief in the immutability of the different forms of life almost universally held in all civilised countries until the middle of the last century. It is true that the suggestion that the world as we see it now is the outcome of a long series of continuous changes, generally similar in kind to those actually taking place around us to-day, had been made by several philosophers in ancient days; whilst from time to time some more advanced thinker would express the belief that every animal, including man, is the lineal descendant of some more primitive type of living creature. But those who held such views were always so few in number that the general acceptance of their beliefs-the practically universal acknowledgment amongst thinking men during the last fifty 
or sixty years of the truth of the principle of evolution-can only be described as a complete revolution in thought. But must not the adoption of the belief that by evolution alone can we account for the visible facts of life tend to produce material alterations in the way in which we regard many practical questions? Is not every revolution in thought inevitably accompanied by more or less considerable changes in policy and social customs? The truth is that it is quite impossible for us to go on acting as if we held precisely the same beliefs as our ancestors; and the aim of the eugenist is both to guide and to hasten the reforms in social customs and in legislation which must in any case result from the acceptance of the doctrine of evolution.

But are any new methods of reform necessary besides those which we are now so earnestly striving to introduce, it may be asked? Anyone who studies our Poor Law statistics, or who looks at our ever-growing lunatic asylums, homes for imbeciles, and hospitals, or who considers our criminal records, or who merely takes a single walk in our city slums-anyone who ponders over the subjects thus brought to his mind must at all events feel profoundly dissatisfied with the existing social condition of his country. Splendid efforts are no doubt now being made on all sides; but, when we remember how long this noble strife has lasted, we are absolutely driven to inquire whether, in addition to all the good now being done, some other and hitherto untried methods are not also essential to secure the progress of the nation, or indeed to safeguard it from decadence. If, as we hold, it will be necessary to continue in the future as in the past to try to alleviate or mitigate the sufferings of our fellow-creatures by the application of immediate remedies, it will be absolutely incumbent on us henceforth also to recognise the necessity of searching for the ultimate sources of all these evils in the light of our ever-advancing knowledge of the laws of nature. In the past the efforts of the social 
reformer have been almost entirely directed to conferring immediate practical benefits on man by altering his mental and physical surroundings. Without relaxing these efforts, we must also in the future endeavour to ensure that our descendants shall actually enter the world with a better natural equipment than that which we possess wherewith to fight the battle of life. As long as complete ignorance prevailed as to the way in which the generations of man succeeded each other, it was inevitable that all philanthropic efforts to help the human being should have begun at his birth. But now that this ignorance is being rapidly dissipated we are bound to see if something cannot be accomplished before his birth; and this is the aim of the eugenist. We hold that the world is so constituted that all the good and useful inborn qualities of man, as well as all his evil tendencies, have been evolved in accordance with what are called the laws of nature; and our hope and belief is that by studying those laws, and by utilising the processes thus discovered by which man has been evolved from some lower type of life, we shall now be able to take steps tending to ensure that the man of the future shall be a far nobler being than the man of to-day.

We eugenists are no doubt not yet in a position to formulate a policy with great precision; and I for one hope that we shall not attempt to do so for a long time to come; because scientific dogmas are apt to be the death of scientific progress. Moreover, when it is remembered that Sir Francis Galton, the founder of our science, wrote his first paper on this subject in the year 1865 , and that we have not therefore yet celebrated the jubilee of this movement, no one ought to be surprised that more has not been done and that much remains still unknown. This fog of doubt, which is largely due to our ignorance of the methods adopted by nature in promoting racial progress, is, however, certainly slowly clearing away; and even now 
through it we believe that we see quite clearly that the selection of the ancestry of the coming generations-the selection of the stock from which the race of the future is to spring-has been at all events one of Nature's main methods of ensuring racial advancement. But if Nature has always as it were paid the closest attention to the factor of heredity in dealing with all animals and plants, and if we wish to see a continuance of the progress thus made in the past, the men of the future becoming healthier, happier, and nobler than the men of to-day because of their superior inborn qualities, surely if this be our aim we clearly see that the duty of studying the question of human heredity is imperatively imposed upon us. In short, whilst we hold that the social reformer should receive every encouragement in his efforts towards the betterment of human surroundings, we eugenists are convinced that it is essential at the same time to adopt certain reforms based on the factor of heredity. Between these two movements-the environmental and the heredity - there need, we think, be no hostility whatever; for both are absolutely necessary to ensure human progress in all directions. The breeders of racehorses do not waste their time in quarrelling as to which is the more important for their horses, good training or good pedigrees; and the breeders of mankind may in large measure leave it an open question which is the more important, environment or heredity. And this is a point which needs emphasising, because misconceptions as to the opinions we hold on these questions have given rise to ill-founded prejudices against us.

The confession which I have just made that the eugenic programme is somewhat indefinite must, however, not be held to imply that there is any lack of work for the eugenist now to do. To convince our fellow-countrymen that human heredity is a subject imperatively demanding our attention; to advocate those moral and legislative reforms which even now we see to be advisable; and to continue those scientific investigations 
which are necessary to enable us to advance with greater confidence in the future-here in all probability is work enough for all our lifetimes. And firmly believing as I do that all who are willing can play some part in thus helping forward this great social movement, I sincerely trust that a eugenic society may be founded in the capital of Scotland, so long the seat both of morality and of science.

My object to-night will merely be to briefly allude to some of the unsolved problems of eugenics, and to indicate some of the ways in which eugenic societies can aid both in their solution and also - and this is perhaps their more important function-in influencing public opinion in the desired directions, in the hope of thus promoting the necessary moral and legislative reforms. But before doing so I should like to suggest to those joining this society that it is well to take some little pains to grasp what is really included within the scope of the science it is especially intended to promote. All who sympathise with this movement will probably have read the well-known definition of eugenics finally adopted by Galton, namely, that it includes " the study of the agencies under social control that may improve or impair the racial qualities of future generations, either physically or mentally." Now that definition might at first sight appear, to those who have grasped its full meaning, to be all that is needed both to avoid misconceptions and to attract the attention of the public to this subject. Experience, however, proves that a definition standing alone is almost useless ; because, amongst other reasons, the meaning it conveys depends in great measure on the mental atmosphere, so to speak, of the inquirer. This definition has been often wholly misunderstood, whilst perhaps still more frequently it has resulted in the mind being focussed on one only of the many branches of this subject. For example, the words "racial qualities" will forcibly recall to the minds of many social reformers what have been described as "racial poisons," including alcohol, lead, etc., and may thus 
lead to the belief that eugenics is mainly concerned with the cure of the undoubted evils arising from such causes. Without going deeply into these vexed questions, a word or two as to how far this view is justifiable may be advantageous.

Though the direct evil effects of alcohol, on those who take it in excess, at all events, as well as the moral and material deterioration of their families, are quite unquestionable, yet the eugenist, looking to the nation in the future, must also inquire whether moderate or hard drinking does affect the descendants of the drinker or the drunkard as regards their innate qualities. On this point we are still in doubt, although many confident assertions have been made. There is, it is true, some evidence to show that the sons and daughters of a drunkard are thus damaged as regards their inborn qualities; but, if we look to the actual biological effects on the third and subsequent generations, we are, in my opinion, in complete ignorance. Moreover, as regards those dread contagious diseases which produce such certain and terrible effects on the children of the diseased, here again the biological consequences to future generations are quite problematical. It seems, then, that the damage done both to the current generation and to their unborn children alone affords ample justification for a campaign against drink and disease, a campaign in which the eugenist should be all the more willing to join because it may yet be proved that these "racial poisons" do injuriously affect posterity for an indefinite number of generations, in which case they would be shown to be eugenic factors of prime importance. We must not, however, neglect the other possible alternative, and we ought to admit that, however vast would be the immediate benefits resulting from the abolition or destruction of racial poisons, yet it may well be that this would not be a step tending to produce a progressive advance in the inborn characters of mankind, which is the true aim of the eugenist. If this be so, surely it follows that, without relaxing our efforts 
in this noble social campaign, we yet should not remain satisfied until we have ascertained whether some steps cannot be taken which would unquestionably produce that most desirable result.

All around us we see efforts being made to improve the environment of the people, efforts with which I have already expressed my sympathy in the most emphatic manner. But with reference to reforms of this type, if we look the facts of life in the face, we must acknowledge that as regards all changes in physical conditions, such as better housing and sanitation, we cannot tell how long the improvements now being made will last, nor do we know whether they will tend automatically to promote any corresponding advance in the inborn qualities of the race. Even if we do not join in the vehement denial of the inheritance of acquired characters, now the attitude commonly adopted in the world of science, yet no one can in truth pretend to estimate the eugenic value, or the value to the generations of the more distant future, of any purely environmental reform. In order that we may stand on firmer ground we eugenists must continue to urge that further inquiry be made as to the biological effects of changes in human surroundings, an inquiry of the greatest difficulty. And, pending the result of such researches, we must continue to point out that if our object be to ensure the continued progress of the race, and if we wish to make certain that we are taking some steps in this direction, we must not confine our attention to reforms affecting environment. But where, then, are we to look if this be our quest? Is it not obviously to the factor of heredity, by means of which the inborn qualities of one generation are passed on to the next, to which we ought mainly to look when taking thought concerning the racial advancement of mankind? In fact, we have by a somewhat different route again reached the conclusion that heredity is the key by means of which the door leading to the future advancement of mankind must be unlocked. 
But even if this view be adopted we have many difficulties to face before we can decide on the practical steps which should now be taken. Let us begin by imagining mankind first arranged in order according to the qualities held to be desirable, and then divided in two equal groups, when there would be one group composed of individuals all above, and another of those all below the average in what Galton called civic worth. This imaginary division having been made, it is no doubt evident that the main aim of the eugenist should be to decrease rate of multiplication in the lower of these two halves of humanity relatively to the rate of multiplication in the upper half; for the greater the success of such efforts, the greater would be the proportion of our descendants who would have sprung from superior stocks, and the more certainly would progress be thus ensured through the agency of heredity. But before the best methods of securing these results can be ascertained, many problems have to be solved, and much hard work must be undertaken. The first question which naturally arouses our attention is whether as a fact our nation is now advancing as regards its inborn qualities, or whether we are degenerating; that is, whether the less fit are multiplying so fast that they are, as it were, swamping the more fit, or whether, the reverse being the case, we are still on the upward path of racial progress. In order to decide in which half of humanity the rate of multiplication is highest, we must obviously have some method of sorting human beings into groups according to their innate qualities, or their biological fitness; and this we have now no means of doing. We can, it is true, generally say whether one group is richer or poorer than another; but does this afford any indication of their relative fitness? Or, in other words, is there any correlation between wealth and innate ability? Here is a problem urgently demanding our attention, to which but little thought has yet been given, and concerning which there is still much doubt. As a single example of the 
way in which an answer to this question may be sought, what is being done by my society in this direction is perhaps worth mentioning. A scheme has been elaborated by means of which a record will, it is hoped, be obtained of the social classes, or the kind of surroundings from which certain boy and girl emigrants are drawn; whilst subsequently efforts will be made to follow their careers in the colonies. These young people go out without parents, and all under much the same conditions, the element of environment being thus more or less completely eliminated; and their innate qualities can therefore be judged by their subsequent success or failure in life. In this way we ought, therefore, in time to be able to ascertain whether these innate qualities do vary according to the social status of the emigrant's family.

If anyone can suggest any other and more ready method of ascertaining the inborn qualities of the different sections of the nation, we shall indeed be grateful; for, as it is, we have to rely mainly on a priori reasoning in considering whether there is any correlation between wealth and innate qualities. Certainly no one can be so foolish as to deny that there are amongst the poor many individuals both very virtuous and very capable, or that amongst the rich many most undesirable specimens are found, by whatever test they may be judged. But it is equally foolish to blind our eyes to the fact that a sifting process is in fact continually in operation; for the naturally strong and able amongst the poor often acquire greater wealth, whilst many of naturally deficient stock amongst the richer classes keep slowly sinking from their more comfortable estate. In fact, it can hardly be doubted that the poorest strata of society do contain an exceptionally large proportion of the biologically unfit; a fact which must fill us with grave alarm when we remember that statistical inquiries prove conclusively that this same section of the community has also an exceptionally high birth-rate. For if the unfit are 
multiplying more rapidly than the fit, this we are certain must inevitably lead to national degeneracy.

But if the relatively low rate of multiplication of the betteroff classes-I am not thinking about the very rich-is a source of danger to the nation, ought we not to consider carefully all possible causes which may account for this alarming fact? If we put aside the possible existence of any direct biological cause for the low fertility of the more cultivated classes, we yet have to inquire whether there are not certain factors acting in this direction in a more indirect manner. Almost everyone is considerably influenced by fears concerning the possibility of a diminution in his own comfort in the future, and also concerning the prosperity of any children he has or may have; and such fears inevitably tend to a postponement of marriage and a diminution in the size of the family. Moreover, such causes obviously affect the well-to-do more than the destitute; because the fear of a fall varies with the depth of the possible drop, those already at the bottom being troubled with no such apprehensions. The man in comfortable circumstances dreads the possibility of his children falling in the social scale, whilst no such thought can enter the head of the pauper. If this be the main cause of the comparative infertility of the more prosperous and presumably, on the average, abler classes, we have next to consider how this national disease may be cured.

In this quest our aim must obviously be, amongst other things, to make respectable parents with families look to their future with greater assurance than they at present feel. Possibly something might be done to increase the now somewhat slender confidence which is felt in regard to the contributions receivable from children in old age; with the result that the production of a family would seem to be less economically undesirable. Then again, it would unquestionably be possible to make the income tax vary substantially according to the 
size of the family, and to deal with death duties in a similar way. Another proposal which ought, I think, to be adopted in this country, is that which has actually been tried at Schöneberg, near Berlin, namely, the adoption of a scale of pay for all govermment employees, dependent in certain measure on the number of their children; for, where none but good workmen are employed, this system would unquestionably be eugenic in its tendencies. In fact, there are several reforms to which the politician can devote his energies with confidence as to their beneficial eugenic results.

The expedients just mentioned for lightening the financial burdens of parenthood would, no doubt, touch but a small percentage of the nation, and more drastic remedies applicable to nearly the whole population are certain to be suggested. For example, a bill has been passed by the House of Representatives of Australia with the object of conferring a bonus of $£ 5$ to the mother of every child of white race at its birth. All such proposals must, however, be scrutinised with great care before they can be endorsed as regards their eugenic effects; for any system designed to increase the birth-rate generally may have the effect of increasing it more in the lower than in the upper half of humanity. If any proposed stimulus would be most felt by the least provident classes, as is probably the case with the Australian example just quoted, the results would almost certainly be dysgenic and not eugenic. In short, it seems that in our campaign we must not rely too much on such economic stimulants, for our main hope must rest on the possibility of changing the whole mental attitude of the nation in regard to the duties which it owes to posterity.

If the explanation of the low fertility of the well-to-do classes is that they pay too much regard to their future economic position, it may with equal truth be said that the high fertility of the destitute results from many of them taking but little thought of their future welfare; for innate mental 
incapacity for forethought often leads to early marriages, large families, and poverty. Although something may be done to mitigate these joint evils by moral persuasion, yet it must be admitted that the prospects of beneficial results thus being obtained in the very lowest strata of society are but very slight. The man who is not in the least deterred from an improvident marriage by the prospect of immediate want is little likely to be open to eugenic or any other argument. A large class, in fact, certainly exists which cannot be touched by any such means, and it is within this class that the vast output of undesirable citizens is taking place which the eugenist is striving to lessen. How can this be done? Possibly some steps might and should be taken in the direction of making those who indulge in reckless marriages feel more immediately the unpleasant economic consequences thus arising; and this would be perfectly legitimate considering that by such marriages they inevitably throw a heavy burden on the shoulders of their more prudent neighbours in the form of increased poor-rates, etc. But if we look the facts of life fearlessly in the face we are driven to the conclusion that, for a large section of the community, the only methods by which the desired lessening of fertility can be obtained are sterilisation and segregation.

As regards sterilisation, I do not propose to discuss this subject to-night at length. In fact, I merely wish to express the opinion that whilst, on the one hand, this question should be approached with the utmost caution and in a most conservative spirit, yet, on the other hand, it would be well to watch carefully what is taking place in America. In eight states of the Union laws have been passed authorising sterilisation in the case of certain classes of degenerates; and, if little has as yet been done under cover of these laws, this may be due to a doubt as to whether they are constitutional, and therefore valid. 
As regards segregation, this method of dealing with undoubted degenerates must now be regarded as well within the region of practical politics; for the eugenic arguments in favour of the Mental Deficiency Bill, though they aroused strong opposition, yet unquestionably carried much weight in many quarters. If we accept the explanation of the high fertility of the unfit already given-namely, that it is due to a certain deficiency on their part in mental powers-we should expect to find that families amongst the definitely feeble in mind are exceptionally large; and this is undoubtedly the case. The Eugenics Education Society had, therefore, had no hesitation whatever in placing the Mental Deficiency Bill in the forefront of their programme, and in promoting it by every available means. This they did by endeavouring to influence members of Parliament in the constituencies, by appearing before private committees in the House of Commons, by speaking at meetings, and by circularising the local authorities throughout the country. The victory has now been won, the bill having passed; but more work of this kind may at any moment become urgently necessary; work in which local eugenic societies could play a most useful part.

Besides semi-political agitation of this kind, serious scientific work is also needed in reference to the mentally defective. We want many more pedigrees of families containing feeble-minded individuals; and these must be collected with all the many precautions needed in such cases. These records are required in order not only to ascertain with greater accuracy the degree of probability of feeble-minded children appearing under given family conditions, but also to solve certain Mendelian problems. For example, is feeble-mindedness a simple recessive character? The asserted fact that when two feeble-minded persons marry, all their children are feeble-minded, points to this conclusion; whilst other facts are said to point to a different view. In 
short, much still remains to be ascertained with regard to many genetic questions.

Eugenists ought, in fact, not to remain satisfied for long either as regards scientific inquiry or practical legislation with dealing with the feeble-minded alone; for there are many other classes of degenerates, notably criminals and paupers, whose multiplication ought to be diminished. In both these classes the trouble is, we believe, closely correlated with inborn mental defects, and more pedigree work is greatly needed in order to enable us to speak with greater confidence concerning the degree of probability of these characteristics being inherited.

Moreover, the whole question of psychological tests demands further attention. It is true that the Binet System has been carefully elaborated in France, by means of which it is held that criminals can be graded according to their mental capacity; whilst Prof. Münsterberg in his Psychology and Crime urges the value of measuring by definite experiment various physical attributes, such as accuracy of perception of touch, in connection with mental degeneracy. In fact, what we want to be able to do, as it seems to me, is to be able to mark out as a class apart those individuals who have been proved to be undesirable or defective as judged by all the three following tests:-

(1) In the case of criminals, by having been convicted of several crimes, the number depending on their gravity; and, in the case of paupers, by having been frequently in and out of the workhouse;

(2) By having been proved, either by evidence or by definite physical or psychological tests, to be either physically or mentally defective; and

(3) By having been reported by the prison or workhouse authorities, as the case may be, to be unable or clearly unwilling to gain an honest livelihood. 
As regards criminals thus judged to be degenerates, they should be dealt with, not as needing punishment, but either as merely requiring either protection against themselves, or control for the purpose of safeguarding the public from present injury or future hereditary taint; that is to say, that they should be treated with great consideration, provided that their periods of confinement are never brief. As regards paupers coming within these three categories, much the same remarks are applicable; and, for their detention, labour colonies ought to be established in the United Kingdom in pursuance of the example set to us by Belgium and Switzerland. Neither with criminals, nor with paupers, should such detention in the first instance be regarded as being necessarily for life; for those whose failure can fairly be attributed in large measure to misfortune ought to have a chance of regaining their freedom in time. Even if a mistake is sometimes made in letting out a veritable degenerate, the evil will probably soon be remedied by his return to prison or to the workhouse. Such systems, in fact, must be judged by their results taken as a whole; and, as regards this proposal, it certainly would have the effect of materially reducing the output of defectives, which is all we can hope to do at present.

Eugenics is therefore, as we have seen, founded on the results of scientific investigation; and, in strengthening its foundations, much remains to be done. But since foundations standing alone are useless, what we have to do is to erect on them a moral superstructure; and here, I am convinced, our greatest difficulties will be felt. Our main object must be to sow broadcast throughout the nation a deep and impelling sense of our obligations towards posterity; a task which may be facilitated in many different ways. Eugenic education societies may be founded in various localities, a step which would prove, I believe, to be most beneficial; for everyone who by joining a society enrols himself as one of our army is quite 
unconsciously thus induced to become an advocate in our favour in general conversation. Moreover, in definite propaganda work such local help is almost indispensable. For example, at Liverpool certain members of the council of the local eugenic society have done excellent service in themselves, giving elementary lectures in eugenics at various institutions, such as workmen's clubs, teachers' associations, etc. Again, such help is needed in making the best use of the local press. Lastly, especial effortis should be made to interest teachers in schools of all kinds in our cause; for, if the eugenic ideal could be properly planted in the minds of all children, not only would the effect be immediately ennobling, but good fruit would in time grow of itself out of this seed in the attitude adopted towards eugenic problems by the men and women of the future.

In conclusion, what I wish to urge most strongly is that it is not only the help of the scientist and the moralist that we need; for we appeal to every class of the community to join us in our fight against national degeneracy. If only it were more widely known-and here the economist could help us-how enormous is the burden now thrown on the community by the presence in our ranks of vast numbers of degenerates, then we should be better able to show how urgent is the need for reform. Increased taxation, often hidden in the form of increased rent; lowered wages; increased prices; diminished aid in times of trouble; and lessened power of competition in times of peace and of defence in times of war-these are the heavy penalties we are now paying for the ignorance and consequent carelessness of our ancestors with regard to the purity of our race. Are we to be equally careless as regards the future, and shall we pass on this taint with undiminished intensity to posterity? If ever we can succeed both in making the facts on which our creed is built more widely known, and in establishing as an accepted truth our belief as 
to the grave danger of rapid national degeneracy, then I am certain we shall only have to appeal to our fellow-countrymen in the name of patriotism, in order to attract sufficient recruits to our ranks to make the success of our cause a certainty. 